\section{Espiritualidade na perspectiva de trabalhadores e futuros trabalhadores: análise dos niveis de domínio por parte de estudantes amazonenses}

\section{Spirituality and (future) workers: levels of domain among students from Amazonas (Brazil)}

\author{
Wanderson da Silva Damião ${ }^{1}$ \\ Yeda Cicera Oswaldo ${ }^{2}$ \\ Almir Martins Vieira ${ }^{3}$
}

\begin{abstract}
Resumo
O presente estudo teve como objetivo identificar os níveis de domínio da inteligência espiritual (QS) por parte de estudantes que participaram de evento acadêmico na Universidade Federal do Amazonas, envolvendo matriculados no ensino médio e no ensino superior, por meio da utilização da Escala de Inteligência Espiritual Integrada (ISIS), desenvolvida por Amram e Dryer (2008). Por meio de abordagem quantitativa, obteve-se participação de 197 respondentes durante o mencionado evento, que responderam questionário elaborado com base na ISIS. Os resultados apontaram predomínio de QS na perspectiva intrínseca, com média classificada como razoável. Houve destaque para três variáveis sociodemográficas no tocante à elevação dos níveis dos domínios da QS entre os respondentes, sendo a idade, a religiosidade e a escolaridade. Concluiu-se que o fator escolaridade proporciona elevação do QS, pois, nos domínios com médias menores (Significado e Graça), os indivíduos com maior escolaridade apresentaram altos níveis nesses domínios.
\end{abstract}

Palavras-chave: Espiritualidade. Inteligência Espiritual. Escala de Inteligência Espiritual Integrada.

\begin{abstract}
The aim of this article was to identify the levels of domain of the Spiritual Intelligence (SQ) among students who took place in an academic event promoted by Federal University of Amazonas, involving high school and college students. Data collection procedures have been leaded by the Integrated Spiritual Intelligence Scale (ISIS), developed by Amram and Dryer (2008). Taking into account the mentioned scale, the study was applied to 197 participants, through an electronic questionnaire based in the ISIS. Results indicated a definition of SQ with a greater emphasis on the intrinsic perspective, as well as an average attributed to the level of SQ classified like reasonable. Three sociodemographic variables have been highlighted for the elevation of the levels of the SQ domains among the respondents: age, religiosity and education. Thus, the study demonstrated that education provides SQ level increasing, since the domains with lower averages (Meaning and Grace), individuals with higher education presented higher levels of these domains.
\end{abstract}

Keywords: Spirituality. Spiritual Intelligence. Integrated Spiritual Intelligence Scale.

\footnotetext{
${ }^{1}$ Doutor em Administração pela Universidade Metodista de Piracicaba (UNIMEP). E-mail: wandersoniprm@hotmail.com

${ }^{2}$ Doutora em Psicologia pela Universidade São Francisco (USF). Professora e pesquisadora da Universidade Metodista de Piracicaba (UNIMEP). E-mail: yeda@yedaoswaldo.com.br

${ }^{3}$ Doutor em Educação pela Universidade Estadual Paulista (UNESP), mestre e graduado em Administração pela

Universidade Metodista de São Paulo. E-mail: almir.vieira@gmail.com
}

Artigo recebido em: 08 de dezembro de 2020. Artigo aceito em 30 de janeiro de 2021. 


\section{Introdução}

O debate sobre a questão da espiritualidade no Brasil, tomando como cenário o ambiente de trabalho, costuma enfrentar o chamado efeito "torre de Babel", em razão de seu baixo consenso teórico (REGO; CUNHA; SOUTO, 2007). A própria analogia em relação ao efeito tem origem da tradição religiosa judaico-cristã: a torre foi idealizada por uma população de Babel (capital do império babilônico), que se uniu e começou a construí-la. Porém, a torre não pode ser concluída, dada uma intervenção divina, que fez com que os homens passassem a falar em idiomas diferentes, repentinamente. Essa confusão resultou na interrupção da construção, pois a comunicação entre os trabalhadores ficou fragmentada, gerando a divisão de grupos e, consequentemente, a separação deles para objetivos diferentes.

Mantidas as proporções deste fato histórico, é razoável assumir que o mesmo fenômeno ocorre com a pesquisa sobre a espiritualidade no ambiente de trabalho (EAT) em âmbito internacional. Esse fato fragmenta e dificulta os avanços nas pesquisas científicas, como registram Arias e Lemos (2015), ao alertarem sobre a necessidade de novos estudos críticos sobre o tema.

Ainda a respeito de indicações para estudos, Roberts e Hess-Hernandez (2018) ressaltam a existência de um campo pouco explorado no que diz respeito às reflexões sobre questões espirituais no cotidiano de trabalho. Os problemas sociais que passam a fazer parte da rotina das organizações, relacionados ao individualismo, tais como o egoísmo, abuso de poder, tratamentos desumanos, estresse, entre outros, podem ser diminuídos por meio da prática da EAT (TENFEN; VENELLI-COSTA; VIEIRA; SANEMATSU, 2019), ressaltando a importância do tema para o momento contemporâneo.

A prática da EAT apresenta-se como um dado facilitador à melhoria das relações interpessoais e aspectos relacionados à dignidade humana, visto que as boas práticas de espiritualidade propiciam desenvolvimento de um ambiente de trabalho mais harmonioso, como também um clima organizacional favorável. Assim, considerando que um indivíduo empregado, em sua maioria, dedica cerca de oito horas do seu dia ao trabalho, o ambiente de exercícios de suas atividades profissionais é altamente influenciador na maneira como age em suas atividades fora da empresa, seja com a família, amigos, vizinhos, ou a própria comunidade (REGO; CUNHA; SOUTO, 2007; 
ŠILINGIENĖ; ŠKEERIENE， 2015; TENFEN; VENELLI-COSTA; VIEIRA; SANEMATSU, 2019).

Segundo Vasconcelos (2015), o avanço da temática também se estabelece na consideração do panorama das primeiras décadas do século XXI, período marcado por rápidas reconfigurações tecnológicas e estruturais das empresas e por novas competências técnicas e comportamentais dos trabalhadores. Ainda segundo o autor, os desenhos organizacionais resultantes desse contexto afetam as relações de trabalho, exigindo do indivíduo respostas emocionais a situações de pressão e cobrança, cenário esse que exige a prática da espiritualidade.

Assim, este trabalho tem por objetivo identificar os níveis de domínio da inteligência espiritual por parte de estudantes trabalhadores e futuros trabalhadores que participaram de evento na Universidade Federal do Amazonas, campus da cidade de Itacoatiara (AM), por meio da utilização da Escala de Inteligência Espiritual Integrada (ISIS), desenvolvida por Amram e Dryer (2008). Para tanto, o artigo é composto por quatro seções, além desta introdução. A seção a seguir apresenta o referencial teórico assumido, com destaque para a descrição da escala utilizada. Em seguida, tem-se a descrição dos procedimentos metodológicos adotados para a pesquisa. A quarta seção apresenta os dados obtidos, com sua respectiva análise e, por fim, a última seção apresenta as considerações finais do estudo.

\section{Referencial Teórico}

\section{A espiritualidade e o indivíduo}

Para se compreender o conceito de espiritualidade, primeiramente é preciso observar que as definições abordam pelo menos três perspectivas: 1) Intrínseca, quando algo faz parte do interior do indivíduo, independente de religião; 2) Religiosa, quando envolve crenças e instituições religiosas; 3) Existencial, quando o indivíduo busca significado pessoal e sentido nas relações sociais, sejam elas com a comunidade, família e trabalho (KRISHNAKUMAR; NECK, 2002; PAIVA, 2015).

A perspectiva antropológica segundo a qual o ser humano possui espírito nos remete, consequentemente, ao fato de que o mesmo possui também um quadro de espiritualidade (MOGGI; BURKHARD, 2004; ZOHAR; MARSHALL, 2017). A partir de tal inferência, Wegel (2019) propõe que a apropriação sobre o indivíduo pode ser feita levando em conta três dimensões básicas: física, emocional e espiritual. 
$\mathrm{Na}$ dimensão física, encontramos as características biológicas, referentes ao corpo. Nessa dimensão, encontramos o que Moggi e Burkhard (2004) classificam como corporeidade, responsável pelas ações práticas dos indivíduos. No tocante à dimensão emocional, encontramos as características psíquicas, classificadas como sistema psíquico. Nessa dimensão, se manifestam e se estabelecem o intelecto, a mente, a memória e a consciência. Nesse campo, o maior destaque deve ser dado para as percepções, comportamentos e personalidades do indivíduo (ZOHAR; MARSHALL, 2017).

Já na dimensão espiritual, encontramos as características teológicas, resultando no sistema racional. Nessa dimensão, se constroem as questões de valores, de sentido, de propósito, de visão e de missão na vida de um indivíduo. Assim, conforme descreve Ferreira (2016), encontra-se o desenvolvimento da espiritualidade, tendo como peçaschave iniciativas como construção e ação, altruísmo e compaixão.

Para que essa espiritualidade ocorra, é fundamental desenvolver o que Zohar e Marshall (2017) denominaram de inteligência espiritual. Essa inteligência é a capacidade de um indivíduo desenvolver valores e propósitos para a sua vida. Quando essa inteligência entra em ação, desenvolve-se a espiritualidade.

Ainda tomando por base as proposições de Zohar e Marshall (2017), a espiritualidade pode ser assumida como um conceito mais amplo que religião (esta é, na verdade, uma expressão da espiritualidade). É um sentimento pessoal, que estimula interesse pelos outros e por si, um sentido de significado da vida capaz de fazer suportar sentimentos debilitantes de culpa, raiva e ansiedade, conforme destacam Antunes e Silva (2015).

Embora não sejam sinônimos, religiosidade e a espiritualidade apresentam destacada relação (CARNEIRO; SERAFIM, 2015). A religiosidade envolve um sistema de culto e doutrina que é compartilhado por um grupo e, portanto, tem características comportamentais, sociais, doutrinárias e valorais específicas. A espiritualidade, por sua vez, está relacionada com o transcendente, com questões definitivas sobre o significado e propósito da vida, além da concepção de que há mais na vida do que aquilo que pode ser visto, ou plenamente entendido (SAAD; MASIERO; BATTISTELLA, 2001; ZOHAR; MARSHALL, 2017).

\section{Inteligência Espiritual}


Segundo Arruda (2005), a inteligência espiritual nas organizações ocorre devido à junção da administração holística com a prática da espiritualidade nos processos de gestão. Assim, a inteligência espiritual pode ser definida como a capacidade do indivíduo desenvolver sua espiritualidade (ŠILINGIENĖ; ŠKEERIENÉ, 2014; UPADHYAY; UPADHYAY, 2016).

Nessa perspectiva, quando uma organização possui a capacidade de desenvolver a espiritualidade dos seus colaboradores, compreende-se que a mesma possui uma inteligência espiritual. Um dos caminhos para esse desenvolvimento é por influência da cultura organizacional, incorporando valores espiritualizados, capazes de serem absorvidos pelos colaboradores. Outro caminho é pelo compartilhamento dos valores pessoais espiritualizados dos colaboradores, capazes de permearem e serem incorporados nos valores da cultura organizacional (ARRUDA, 2005; MOGGI; BURKHARD, 2004; DAMIÃO; VIEIRA; SPERS; CASTRO, 2017).

Roberts e Hess-Hernandez (2018) destacam a existência de um novo quociente, o da inteligência espiritual (QS). Este quociente permite analisar questões essenciais da vida e parece ser, na expressão dos autores, uma "chave para um novo tempo", onde a ciência parece tocar em questões que anteriormente eram abordadas apenas por teólogos e filósofos. Arruda (2005) e Pinho (2015) explicam que o desenvolvimento da inteligência espiritual (QS) ocorre como uma mudança de paradigma, transcendendo a inteligência intelectual (QI) e a inteligência emocional (QE).

Segundo analogia feita por Kalantarkousheh, Sharghib, Soleimanib e Ramezanib (2014), o QI compreende um paradigma da administração tradicional, focado na lógica e nos resultados. Já o QE compreende um fator diferencial, capaz de gerar um avanço competitivo por buscar compreender e se beneficiar dos fatores emocionais que geram resultados benéficos. O QS passou a receber foco devido à busca do autoconhecimento, evolução e equilíbrio, que passaram ser o anseio das organizações do século XXI.

Ter um alto quociente espiritual (QS) implica ser capaz de usar o espírito para ter uma vida mais rica e mais cheia de sentido, adequado senso de finalidade e direção pessoal. O QS aumenta horizontes e torna os indivíduos mais criativos, ou seja, uma inteligência que impulsiona a abordagem para problemas de sentido e valor. O QS está ligado à necessidade humana de ter propósito de vida, sendo utilizado para desenvolver valores éticos e crenças que norteiam ações. (ARRUDA, 2005; PINHO, 2015).

A QS também passou a ser uma possível resposta de solução aos problemas das 


\section{DAMIÃO; OSWALDO; VIEIRA}

organizações contemporâneas, em dilemas como lucro a qualquer custo, corrupção,, falta de respeito humano e ambiental e disputas, para se mencionar alguns exemplos.

Os resultados dessas ações organizacionais têm sido o desequilíbrio emocional e social, interno e externo às organizações. No tocante ao desequilíbrio interno, a questão está diretamente relacionada aos problemas psíquicos que passam a acometer os colaboradores de determinada organização, bem como o clima organizacional ruim que colabora para o desenvolvimento dos problemas psíquicos. Já os problemas externos referem-se à influência que os fatores internos passam a exercer nos colaborares, que tendem a manifestar os mesmos problemas psicossociais do ambiente de trabalho nos contextos sociais externos (família e círculos de amizade) (ZOHAR; MARSHALL, 2017).

Amram e Dryer (2008) consideram que a QS é um conjunto de habilidades que as pessoas usam para aplicar, manifestar e incorporar recursos espirituais, valores e qualidades de modo a melhorar o funcionamento e o bem-estar diário. Essas habilidades podem ocorrer em maior ou menor grau, e a prática ou treinamento pode ajudar as pessoas a desenvolver algumas (ou todas) dessas habilidades.

\section{Escala de Inteligência Espiritual}

O desenvolvimento e validação preliminar da Escala de Inteligência Espiritual Integrada (ISIS), por Amram e Dryer (2008), sugere que o QS contribui para o bemestar e pode ser diferenciado da espiritualidade e/ou experiência espiritual, crença ou orientação. Na utilização da ISIS, o indivíduo avaliado deve marcar todos os itens em uma escala de 1 a 6 , com base na frequência do seu comportamento nos últimos 6 a 12 meses. A pontuação da escala considera: 1 - Nunca ou quase nunca; 2 - Muito raramente; 3 - Pouco frequentemente; 4 - Com alguma frequência; 5 - Muito frequentemente; 6 - Sempre ou quase sempre.

Dessa forma, na composição da ISIS, busca-se avaliação de 5 domínios:

1. Consciência: Desenvolvimento de consciência refinada e autoconhecimento, apresentando conhecimento intuitivo, mindfulness e práticas espirituais transracionais.

2. Graça: Vivendo em alinhamento com o sagrado, manifestando confiança e amor pela vida que é baseada na gratidão, beleza e alegria. 


\section{DAMIÃO; OSWALDO; VIEIRA}

3. Significado: experimentar significância nas atividades diárias através de um senso de propósito e um chamado por serviço, inclusive diante da dor e do sofrimento.

4. Transcendência: Ultrapassar o eu ego separado em uma totalidade interconectada, incluindo a visão de mundo de um sistema holístico e o cultivo de relações humanas através de empatia, compaixão, benevolência e orientação.

5. Verdade: Viver em aceitação aberta, perdão, curiosidade e amor por tudo o que se é (toda a criação), incluindo o respeito pela sabedoria de múltiplas tradições espirituais.

O quadro 1, a seguir, apresenta os 82 itens de avaliação utilizados para validar a ISIS.

\section{Quadro 1. Itens de Avaliação da QS}

\begin{tabular}{|c|c|c|}
\hline 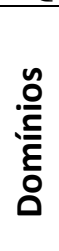 & 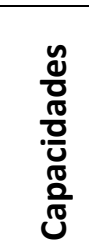 & Itens de Avaliação \\
\hline \multirow{3}{*}{ 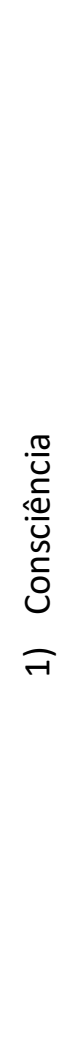 } & 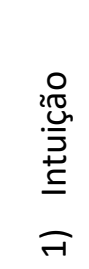 & $\begin{array}{l}\text { Eu presto atenção aos meus sonhos para ganhar insight para a minha vida. } \\
\text { Eu ouço profundamente tanto o que está sendo dito, quanto o que não está } \\
\text { sendo dito. } \\
\text { Escuto minha intuição, para fazer escolhas importantes. } \\
\text { Eu lembro de considerar o que é dito, de forma escondida ou oculto. }\end{array}$ \\
\hline & 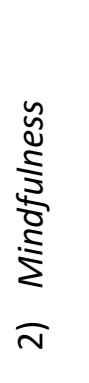 & $\begin{array}{l}\text { Eu procuro e tento descobrir pontos cegos. } \\
\text { Ao discutir ou negociar, eu sou capaz de ver as coisas do ponto de vista da outra } \\
\text { pessoa, mesmo quando eu discordo. } \\
\text { Eu vivo e atuo com consciência da minha mortalidade. } \\
\text { Nas conversas, eu paro várias vezes para voltar atrás, observar e reavaliar a } \\
\text { situação. } \\
\text { Durante uma atividade ou conversa, eu monitoro e percebo meus pensamentos } \\
\text { e emoções. }\end{array}$ \\
\hline & 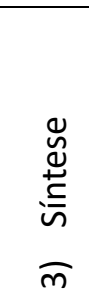 & $\begin{array}{l}\text { Mesmo no meio do conflito, eu olho para e encontrar conexão e pontos em } \\
\text { comum. } \\
\text { Para resolver problemas, eu uso minha capacidade de manter, aceitar e ir além } \\
\text { dos paradoxos. } \\
\text { Eu posso me manter verdadeiro e íntegro diante de pontos de vista } \\
\text { contraditório ou conflitantes. }\end{array}$ \\
\hline
\end{tabular}




\begin{tabular}{|c|c|c|}
\hline \multirow{6}{*}{$\begin{array}{l}\text { त } \\
\frac{\pi}{0} \\
\stackrel{\pi}{0}\end{array}$} & $\begin{array}{l}\stackrel{\mathbb{N}}{\mathscr{Q}} \\
\stackrel{\Phi}{Ð} \\
\stackrel{\sigma}{\sigma}\end{array}$ & $\begin{array}{l}\text { Eu noto e aprecio a beleza que é descoberta em minhas atividades. } \\
\text { Eu aprecio o desfruto e a beleza de minha vida diária. } \\
\text { Eu encontro maneiras de expressar meu verdadeiro eu criativamente. }\end{array}$ \\
\hline & 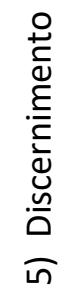 & $\begin{array}{l}\text { Minhas ações estão alinhadas com a minha alma - minha verdadeira essência. } \\
\text { Eu estou ciente da minha verdade interior - minhas verdades internas. } \\
\text { As minhas ações estão alinhadas com os meus valores. } \\
\text { Tenho dificuldade em manter-me firme nas minhas verdades interiores - o que } \\
\text { eu sei por dentro para ser verdadeiro (pontuação reversa) }\end{array}$ \\
\hline & $\begin{array}{l}\frac{0}{\frac{\pi}{\pi}} \\
\frac{\pi}{0} \\
\frac{0}{0} \\
\frac{0}{6}\end{array}$ & $\begin{array}{l}\text { Porque eu sigo o convencional, eu não sou tão bem-sucedido quanto eu poderia } \\
\text { ser (pontuação reversa). } \\
\text { Eu percebo quando meu propósito requer "despadronização", pensamento "fora } \\
\text { da caixa", ou tomar uma posição impopular. } \\
\text { Tenho momentos difíceis quando vou contra convenções, expectativas ou regras } \\
\text { (pontuação reversa). }\end{array}$ \\
\hline & $\begin{array}{l}\frac{2 \pi}{0} \\
\frac{20}{0} \\
\frac{\pi}{0} \\
\end{array}$ & $\begin{array}{l}\text { Minha vida é um presente e tento fazer o melhor de cada momento. } \\
\text { Eu me lembro de sentir-me grato pela abundância de coisas positivas na minha } \\
\text { vida. }\end{array}$ \\
\hline & 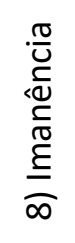 & $\begin{array}{l}\text { Eu estou ciente dos cinco sentidos do meu corpo durante minhas tarefas diárias. } \\
\text { Na minha vida diária, estou desconectado da natureza (pontuação reversa). } \\
\text { Eu passo tempo na natureza para me lembrar do propósito maior. } \\
\text { Eu aprecio as pequenas coisas vida, como tomar banho, escovar os dentes ou } \\
\text { comer. }\end{array}$ \\
\hline & 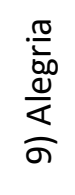 & $\begin{array}{l}\text { Eu conservo um sentimento de alegria nas minhas atividades. } \\
\text { Mesmo quando pareço ter poucas escolhas, sinto-me livre. } \\
\text { Estou frustrado pela minha incapacidade de encontrar significado na minha vida } \\
\text { diária (pontuação reversa). }\end{array}$ \\
\hline \multirow{2}{*}{ 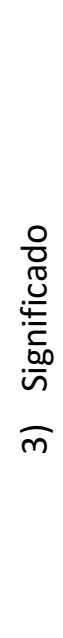 } & 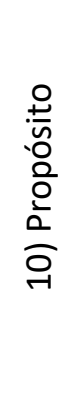 & $\begin{array}{l}\text { Eu tenho meu trabalho como algo sagrado. } \\
\text { Minhas atividades do dia-a-dia, estão alinhadas com meu propósito } \\
\text { independente do que acontecer no mundo. } \\
\text { Vejo as recompensas financeiras como sendo o objetivo principal do meu } \\
\text { trabalho (pontuação reversa). } \\
\text { Eu vejo o avanço da minha carreira como a principal razão para fazer um bom } \\
\text { trabalho (pontuação reversa). } \\
\text { Eu encontro significado na dor e sofrendo na minha vida. }\end{array}$ \\
\hline & 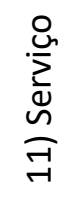 & $\begin{array}{l}\text { Eu sinto que meu trabalho é uma expressão de amor. } \\
\text { Meu trabalho está alinhado com meu propósito maior. } \\
\text { Em minha vida diária, sinto que meu trabalho é em serviço para o todo. }\end{array}$ \\
\hline
\end{tabular}




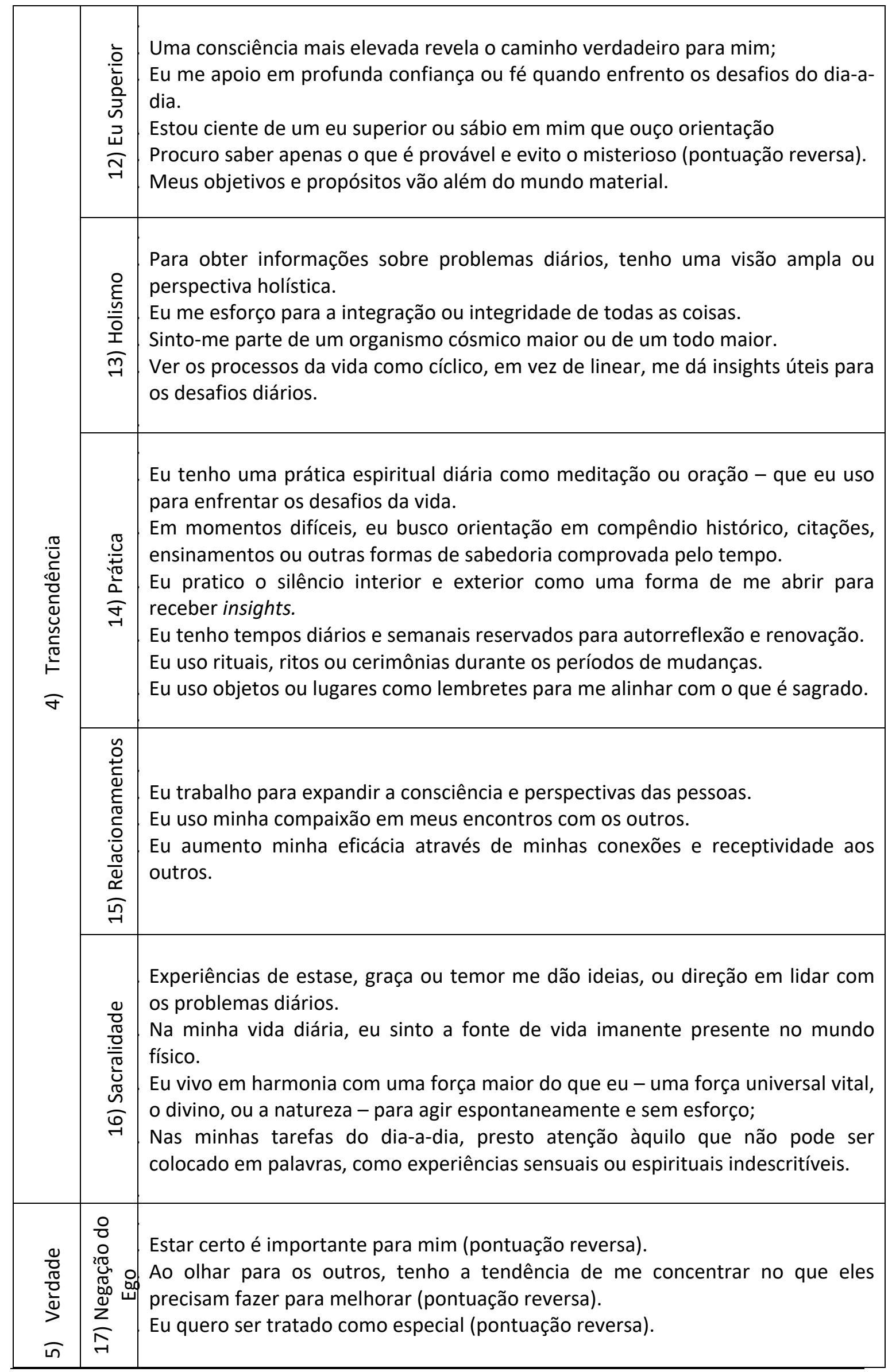

Revista Eletrônica Gestão e Serviços v.11, n. 2, pp. 3130 - 3149, Julho/Dezembro 2020.

ISSN Online: 2177-7284 e-mail: $\underline{\text { regs@ } @ \text { metodista.br }}$ 


\begin{tabular}{|c|c|}
\hline 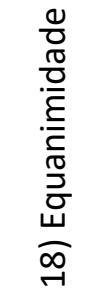 & $\begin{array}{l}\text { Quando as coisas são caóticas, eu permaneço ciente do que está acontecendo } \\
\text { sem se perder na minha experiência } \\
\text { Eu fico chateado quando as coisas não seguem o caminho que eu quero } \\
\text { (pontuação reversa). } \\
\text { Mesmo quando as coisas são perturbadoras e caóticas ao meu redor, eu } \\
\text { permaneço centrado e pacífico por dentro. }\end{array}$ \\
\hline 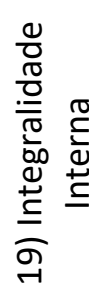 & $\begin{array}{l}\text { Eu sou meu pior inimigo (pontuação reversa). } \\
\text { Eu tenho dificuldade em integrar várias partes da minha vida (pontuação } \\
\text { reversa). } \\
\text { Eu aceito-me como sou com todos os meus problemas e limitações. } \\
\text { Eu não sei como ser eu mesmo em interações com os outros (pontuação } \\
\text { reversa). }\end{array}$ \\
\hline 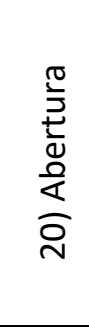 & $\begin{array}{l}\text { Eu resisto a eventos dos quais não gosto, mesmo quando precisam ocorrer } \\
\text { (pontuação reversa) } \\
\text { Eu tenho ressentimento em relação àqueles que me prejudicaram (pontuação } \\
\text { reversa) } \\
\text { Acho frustrante quando não sei qual é a verdade (pontuação reversa). } \\
\text { Eu resisto fortemente a experiências que considero desagradáveis (pontuação } \\
\text { reversa). }\end{array}$ \\
\hline 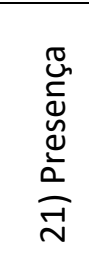 & $\begin{array}{l}\text { Minha mente se afasta do que eu estou fazendo (pontuação reversa). } \\
\text { Acho desconcertante imaginar que não alcançarei o desfecho desejado } \\
\text { (pontuação reversa). } \\
\text { Eu penso no futuro ou no passado sem prestar atenção ao momento presente } \\
\text { (pontuação reversa). }\end{array}$ \\
\hline 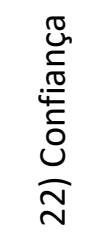 & $\begin{array}{l}\text { Eu sou dirigido e governado por medos (pontuação reversa). } \\
\text { Estou limitado em minha vida pela sensação de que tenho pouquíssimas opções } \\
\text { disponíveis para mim (pontuação reversa) } \\
\text { Eu espero o pior da vida, e é isso que eu costumo vivenciar (pontuação reversa). } \\
\text { Eu tenho fé e confiança de que as coisas funcionarão para o melhor. }\end{array}$ \\
\hline
\end{tabular}

Fonte: Adaptado de Amram e Dryer (2008).

\section{Procedimentos Metodológicos}

A pesquisa caracteriza-se como descritiva e exploratória. Segundo Marconi e Lakatos (2002, p. 18), a "pesquisa social é um processo que utiliza metodologia científica, por meio da qual se podem obter novos conhecimentos no campo da realidade social". Obteve-se, para este estudo, uma amostra por conveniência, com abordagem voluntária e critério de concordância (VERGARA, 2005). Foi aplicado um survey, indicado quando se trata de um procedimento de coleta de dados que utiliza questionários (HAIR JR. et al., 2014; GIL, 2010). 
Participaram da pesquisa estudantes trabalhadores e futuros trabalhadores que participaram do evento denominado "Semana de Ciência e Tenologia da UFAM", realizado no campus da cidade de Itacoatiara, da Universidade Federal do Amazonas (UFAM). O evento contou com a participação de discentes das áreas de ciências biológicas, exatas e humanas. Mesmo sendo realizado em uma universidade federal, o evento envolveu também estudantes do ensino médio da região, o que possibilitou avaliar (também) fatores concernentes à faixa etária dos participantes. Os referidos estudantes (197, no total) responderam questionário elaborado para identificar níveis de espiritualidade, utilizando-se a escala validada por Amram e Dryer (2008), denominada ISIS, em sua versão resumida. As perguntas foram respondidas com atribuição de notas usando uma escala do tipo Likert (6 pontos): 1- nunca ou quase nunca; 2- muito raramente; 3- raramente; 4- com alguma frequência; 5- frequentemente; 6- sempre ou quase sempre.

$\mathrm{O}$ instrumento para coleta de dados foi composto por questões sociodemográficas e pela própria ISIS, sendo disponibilizado pelo site Google Forms, especializado em serviços de questionário. O site permitiu gerar um link aos respondentes, impedindo que um mesmo link fosse respondido duas vezes, controlando as respostas por endereço IP. Os respondentes foram orientados sobre o preenchimento durante a Semana de Ciência e Tecnologia da UFAM, ocasião na qual puderam preencher o questionário durante (ou após) o evento. Também se disponibilizou versão impressa do questionário, de forma que o respondente escolhesse a opção que melhor lhe convinha. Os questionários respondidos em folhas impressas foram digitados/inseridos posteriormente no site Google Forms, de modo a permitir organização dos dados por meio de uma única planilha para a análise estatística.

Os dados coletados formaram um banco de dados para tratamento no software estatístico Statistical Package for the Social Sciences (SPSS), versão 18.0, e no software Past, versão 3.0.

Como critério de inclusão da amostra, os participantes selecionados foram os discentes que assinalaram no questionário digital ou impresso, que responderam às perguntas com sinceridade (algo a ser apontado no instrumento). Os casos em que o participante assinalou não ter sido sincero e verdadeiro em suas respostas foram excluídos da análise. Assim, três pessoas foram desconsideradas no estudo. A pesquisa contou com a participação de 197 inscritos no evento Semana de Ciência e Tecnologia 
da UFAM, que aconteceu entre os dias 16 e 20 de setembro de 2019.

\section{Análise dos Resultados}

Os dados foram organizados com base no número de respostas para cada classificação, dentro de cada domínio, considerando o máximo de QS no valor de 6,0 e o mínimo de 1,0. Tal qual apontam Amram e Dryer (2008), o nível de QS de um indivíduo é medido em referência aos níveis de 5 (cinco) domínios, sendo: Consciência, Graça, Significado, Transcendência e Verdade.

A média das respostas aponta para um maior nível nos domínios Graça $(4,26)$, Consiência $(4,23)$ e Transcendência $(3,96)$, consideradas moderadamente altas. Para o domínio Verdade, a inteligência espiritual média foi de 3,66, e para Significado foi 3,26, sendo consideradas medianas. Assim, dos 197 participantes analisados estatisticamente, tem-se a média de QS apontada no gráfico 1.

\section{Gráfico 1. Média do Nível de QS dos Participantes}

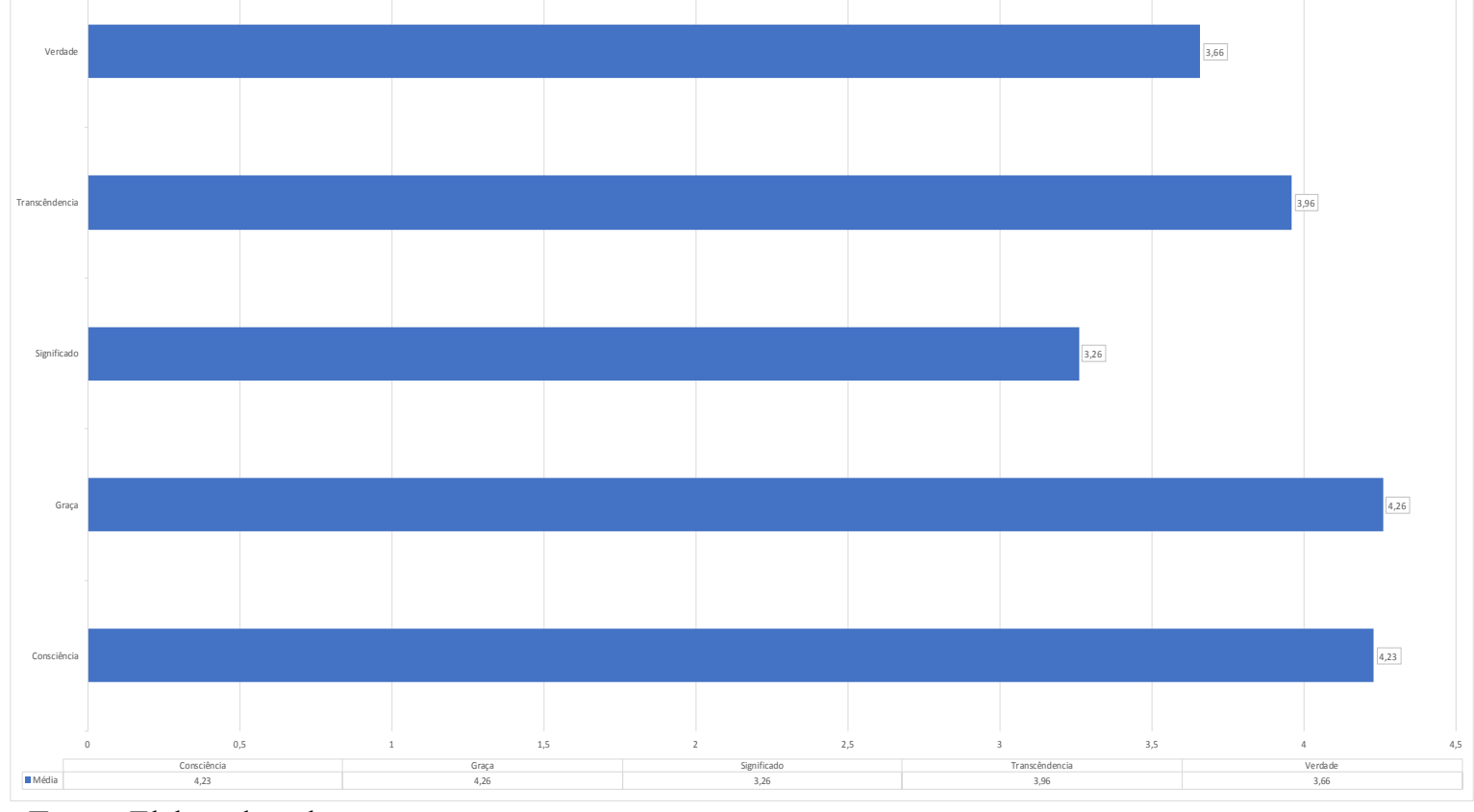

Fonte: Elaborado pelos autores.

Para análise da correlação dos dados totais entre domínios, cada indivíduo teve sua média de respostas calculada por domínio. Por exemplo, como o domínio Consciência possuia seis perguntas, dividiu-se a somatória dos resultados por seis; foram realizados também testes de normalidade com os dados para cada domínio.

Para aferir se existia relação entre os domínios (Consciência, Graça, Significado, 
Transcendência e Verdade), calculou-se o Coeficiente de Correlação de Spearman, que varia de -1 (para relação perfeitamente negativa) a +1 (para relação perfeitamente positiva). Quanto mais próximo ao valor -1 ou +1 , mais forte é a correlação entre as variáveis. Para facilitar a interpretação da correlação, utilizou-se o critério adotado por Evans (1996), conforme o quadro 2. A análise de correlação foi realizada com o software Past, versão 3.0.

\section{Quadro 2. Interpretação do coeficiente de correlação de Spearman}

\begin{tabular}{|llll|}
\hline $0,00 \mid---0,20$ & positiva muito fraca & $0,00 \mid----0,20$ & negativa muito fraca \\
$0,20 \mid---0,40$ & positiva fraca & $0,20 \mid----0,40$ & negativa fraca \\
$0,40 \mid---0,60$ & positiva moderada & $0,40 \mid----0,60$ & negativa moderada \\
$0,60 \mid---0,80$ & positiva forte & $0,60 \mid----0,80$ & negativa forte \\
$0,80 \mid---1,00$ & positiva muito forte & $0,80 \mid----1,00$ & negativa muito forte \\
\hline
\end{tabular}

Fonte: Elaborado pelos autores.

Os testes de permutação apontaram para correlações significativas entre os domínios Consciência (C) e Graça (G) (positiva moderada), Consciência (C) e Transcendência (T) (positiva e moderada), Graça $(G)$ e Transcendência (T) (positiva forte) e Graça (G) e Verdade (V) (positiva fraca), tal qual se constata pelos dados da tabela 1. Estes domínios apresentam clara relação entre si, sendo que, quando o indivíduo apresenta alto nível em um domínio, existe a tendência de também apresentar com alto nível para outros. O domínio Significado (S) foi o único não correlacionado com nenhum outro domínio. Uma das explicações possíveis é a baixa quantidade de perguntas para este domínio; outra explicação seria que este domínio, de fato, não apresenta forte relação com os demais, como demonstram os dados da tabela 1.

Tabela 1. Coeficiente de Correlação de Spearman entre os domínios

\begin{tabular}{cccccc}
\hline & $\mathrm{C}$ & $\mathrm{G}$ & $\mathrm{S}$ & $\mathrm{T}$ & $\mathrm{V}$ \\
\hline $\mathrm{C}$ & - & $<0,001$ & 0,77 & $<0,001$ & 0,81 \\
$\mathrm{G}$ & 0,56 & - & 0,09 & $<0,001$ & $<0,001$ \\
$\mathrm{~S}$ & $-0,02$ & $-0,12$ & - & 0,97 & 0,78 \\
$\mathrm{~T}$ & 0,59 & 0,62 & 0,00 & - & 0,52 \\
$\mathrm{~V}$ & 0,02 & 0,26 & 0,02 & 0,05 & - \\
\hline
\end{tabular}

Fonte: Elaborado pelos autores.

Conforme os valores encontrados, elaborou-se a classificação dos mesmos conforme se indica na tabela 2 , na qual consta o resumo da interpretação da média das respostas da pesquisa acerca da inteligência espiritual. A classificação foi realizada para 
cada gênero, idade, escolaridade, área de atuação, presença de religiosidade, presença de inteligência espiritual no trabalho e entendimento sobre inteligência espiritual.

\begin{tabular}{lc} 
Tabela 2. Classificação da Inteligência Espiritual \\
\hline Muito elevado & $5,1-6,0$ \\
Elevado & $4,1-5,0$ \\
Razoável & $3,1-4,0$ \\
Baixo & $2,1-3,0$ \\
Muito baixo & $1,1-2,0$ \\
\hline
\end{tabular}

Fonte: Elaborado pelos autores.

Não houve diferenças significativas entre as respostas para os gêneros feminino e masculino para todos os domínios (tabela 3), pois as medianas entre os gêneros para cada domínio pouco apresentaram diferenças. Na tabela 3, encontram-se as Medianas (Md) para o gênero feminino (F) e masculino (M), com resultados do teste de MannWhitney, com teste U e probabilidades (p). Esses dados indicam a classificação geral para o nível de inteligência espiritual deste quesito.

Tabela 3. Medianas referentes ao gênero

\begin{tabular}{lccccc}
\hline Domínio & Md F & Md M & U & p & Classificação \\
\hline Consciência & 4,33 & 4,33 & 4141,50 & 0,453 & Elevado \\
Graça & 4,31 & 4,38 & 4378,50 & 0,904 & Elevado \\
Significado & 3,50 & 3,50 & 4299,50 & 0,741 & Razoável \\
Transcendência & 4,00 & 3,91 & 4342,50 & 0,829 & Razoável \\
Verdade & 3,67 & 3,75 & 4216,00 & 0,580 & Razoável \\
\hline
\end{tabular}

Fonte: Elaborado pelos autores.

Houve diferença significativa entre as respostas de solteiros e casados para o domínio Verdade (tabela 4). A mediana para o estado cível "casado" $(4,13)$ foi superior em relação aos solteiros $(3,27)$. Para o domínio Significado, o valor estatístico de probabilidade foi inferior a 0,10 . É provável que um aumento de amostragem fosse suficiente para o resultado ter sido significativo. Apesar de as medianas terem sido iguais, houve proporção muito maior de respostas negativas dos solteiros em relação aos casados, cenário que indica que os casados parecem possuir inteligência espiritual maior para o domínio Verdade. Na tabela 4, encontram-se as Medianas (Md) para os estados civis casado (C) e solteiro (S), com resultados do teste de Mann-Whitney, do teste U, e de probabilidades (p).

Tabela 4. Classificação do nível de QS referente ao estado civil

$\begin{array}{llllll}\text { Domínio } & \text { Md C } & \text { Md S } & \text { U } & \text { p-level } & \text { Classificação }\end{array}$




\begin{tabular}{cccccc} 
Consciência & 4,33 & 4,33 & 1764,50 & 0,607 & Elevado \\
Graça & 4,35 & 4,38 & 1886,00 & 0,981 & Elevado \\
Significado & 3,50 & 3,50 & 1481,00 & 0,097 & Razoável \\
Transcendência & 4,32 & 3,91 & 1506,00 & 0,120 & Elevado \\
Verdade & 4,13 & 3,67 & 1407,00 & 0,050 & Razoável \\
\hline
\end{tabular}

Fonte: Elaborado pelos autores.

Em relação ao domínio Transcendência, houve diferença significativa entre as respostas de pessoas possuidoras de religião e das pessoas que não indicaram assumir religiosidade, sendo maior para os possuidores de religião (tabela 5). As medianas para pessoas com religião $(4,09)$, foi superior em comparação com as pessoas sem religião $(3,55)$. Assim, na tabela 5, encontram-se as Medianas (Md) para a presença de religiosidade (R) e ausência (A), com resultados do teste de Mann-Whitney, do teste U, e de probabilidades $(\mathrm{p})$.

Tabela 5. Classificação para o nível de QS referente à religiosidade

\begin{tabular}{cccccc}
\hline Domínio & Md R & Md A & U & p-level & Classificação \\
\hline Consciência & 4,33 & 4,33 & 2818,00 & 0,638 & Elevado \\
Graça & 4,38 & 4,35 & 2655,50 & 0,320 & Elevado \\
Significado & 3,50 & 3,50 & 2686,00 & 0,370 & Razoável \\
Transcendência & 4,09 & 3,55 & 1629,50 & 0,001 & Razoável \\
Verdade & 3,71 & 3,75 & 2900,00 & 0,837 & Razoável \\
\hline
\end{tabular}

Fonte: Elaborado pelos autores.

No ambiente de trabalho, houve diferença estatística para o domínio Transcendência (Tabela 6), sendo maior para os que praticam inteligência espiritual. A mediana para os que praticam QS $(4,36)$ foi superior aos que não praticam $(3,91)$. Para o domínio Consciência, o resultado foi marginalmente significativo para os praticantes.

$\mathrm{Na}$ tabela 6, apresentam-se as Medianas $(\mathrm{Md})$ para prática de inteligência espiritual no trabalho $(\mathrm{S})$ e "não prática" da mesma $(\mathrm{N})$ com resultados do teste de Mann-Whitney, do teste U, e de probabilidades (p).

Tabela 6. Classificação para o nível de QS no trabalho

\begin{tabular}{cccccc}
\hline Domínio & Md S & Md N & U & p-level & Classificação \\
\hline Consciência & 4,67 & 4,33 & 1453,00 & 0,100 & Elevado \\
Graça & 4,46 & 4,38 & 1502,00 & 0,167 & Elevado \\
Significado & 3,50 & 3,50 & 1679,50 & 0,655 & Razoável \\
Transcendência & 4,36 & 3,91 & 1352,50 & 0,030 & Elevado \\
Verdade & 3,67 & 3,83 & 1612,00 & 0,422 & Razoável \\
\hline
\end{tabular}

Fonte: Elaborado pelos autores.

Para as faixas etárias, não houve diferenças significativas segundo o teste de 
Kruskall-Wallis (Tabela 7), sendo que as Medianas (Md) para as diferentes idades constam na tabela 7 , também com resultado do teste $\mathrm{H}$, e de probabilidades (p).

Tabela 7. Classificação para o nível de QS referente à idade

\begin{tabular}{cccccccc}
\hline Domínio & Md 15|---20 & Md 20|---25 & Md 25|---30 & Md $\mid \mathbf{3 0}---$ & H & p & Classificação \\
\hline Consciência & 4,50 & 4,33 & 4,50 & 4,67 & 0,77 & 0,86 & Elevado \\
Graça & 4,30 & 4,38 & 4,46 & 4,38 & 0,78 & 0,85 & Elevado \\
Significado & 3,00 & 3,50 & 3,50 & 3,50 & 4,26 & 0,23 & Razoável \\
Transcendência & 3,91 & 4,00 & 4,14 & 4,36 & 1,62 & 0,66 & Razoável \\
Verdade & 3,67 & 3,58 & 3,83 & 3,92 & 3,91 & 0,27 & Razoável \\
\hline
\end{tabular}

Fonte: Elaborado pelos autores.

Não houve diferenças estatísticas entre estes graus de escolaridade (tabela 8).

Aparentemente, para os domínios Graça e Verdade, o aumento da amostragem demonstraria maior inteligência espiritual para pessoas com maior grau de escolaridade, uma vez que as medianas para Graduação e Pós-Graduação foram bastante superiores àqueles do ensino médio. Assim, na tabela 8 , constam os valores das Medianas $(\mathrm{Md})$ para os diferentes graus de escolaridade, concluinte do ensino médio (EM), concluinte da graduação (GR) e concluinte de Pós-Graduação (PG), com resultados do teste de Kruskall-Wallis, do teste $\mathrm{H}$, e de probabilidades (p).

Tabela 8. Classificação para o nível de QS referente ao grau de escolaridade

\begin{tabular}{ccccccc}
\hline Domínio & Md EM & Md GR & Md PG & H & p & Classificação \\
\hline Consciência & 4,33 & 4,50 & 4,33 & 2,22 & 0,33 & Elevado \\
Graça & 4,08 & 4,38 & 4,38 & 4,33 & 0,11 & Elevado \\
Significado & 3,00 & 3,50 & 3,50 & 1,33 & 0,52 & Razoável \\
Transcendência & 3,82 & 4,00 & 3,73 & 0,23 & 0,89 & Razoável \\
Verdade & 3,58 & 3,75 & 3,92 & 4,44 & 0,11 & Razoável \\
\hline
\end{tabular}

Fonte: Elaborado pelos autores.

Não houve diferenças estatísticas entre as áreas científicas de estudo, como se pode observar nos dados da tabela 9, na qual constam as Medianas (Md) para as diferentes áreas de atuação: Biológicas (B), Exatas (E) e Humanas (H), com resultados do teste de Kruskall-Wallis, do teste H, e de probabilidades (p).

Tabela 9. Classificação para o nível de QS referente à área científica

\begin{tabular}{ccccccc}
\hline Domínio & Md B & Md E & Md H & H & p & Classificação \\
\hline Consciência & 4,50 & 4,33 & 4,42 & 0,33 & 0,85 & Elevado \\
Graça & 4,46 & 4,38 & 4,19 & 1,74 & 0,42 & Elevado \\
Significado & 3,50 & 3,50 & 3,50 & 0,16 & 0,92 & Razoável \\
Transcendência & 3,91 & 4,00 & 4,18 & 0,32 & 0,85 & Razoável
\end{tabular}




\begin{tabular}{lllllll} 
Verdade & 3,83 & 3,75 & 3,63 & 1,99 & 0,37 & Razoável \\
\hline
\end{tabular}

Fonte: Elaborado pelos autores.

O teste de Kruskall-Wallis demonstrou haver diferenças significativas para os domínios Graça e Verdade em relação ao entendimento sobre QS, bem como sua perspectiva (tabela 10). Quanto à perspectiva do entendimento de QS, buscou-se fazer a adaptação com referência aos conceitos de Krishnakumar e Neck (2002). Assim, o respondente que descreveu seu entendimento sobre QS foi classificado de acordo com 4 categorias: não possui entendimento; entendimento na perspectiva existencial; entendimento na perspectiva intrínseca; entendimento na perspectiva religiosa.

Para o domínio Graça, a resposta com perspectiva de espiritualidade Existencial foi significativamente superior à perspectiva Religiosa e, para o domínio Verdade, a resposta na perspectiva Religiosa foi superior à perspectiva Existencial, segundo o teste a posteriori de medianas. Na Tabela 10, é possível visualizar as Medianas (Md) para as diferentes respostas quanto ao entendimento de inteligência espiritual, na classificação Existencial (E), Intrínseca (I) ou Religiosa (R), com resultados do teste de KruskallWallis, do teste $\mathrm{H}$, e de probabilidades (p).

Tabela 10. Classificação para o nível de QS e seu entendimento

\begin{tabular}{ccccccc}
\hline Domínio & Existencial & Intrínseca & Religiosa & H & p & Classificação \\
\hline Consciência & 4,50 & 4,50 & 4,00 & 5,31 & 0,07 & Elevado \\
Graça & 4,46 & 4,46 & 4,04 & 6,06 & 0,05 & Elevado \\
Significado & 3,50 & 3,25 & 3,50 & 1,59 & 0,45 & Razoável \\
Transcendência & 4,18 & 4,36 & 3,64 & 3,24 & 0,19 & Elevado \\
Verdade & 3,42 & 3,75 & 3,91 & 5,84 & 0,05 & Razoável \\
\hline
\end{tabular}

Fonte: Elaborado pelos autores.

De modo geral, considerando os dados obtidos, a média dos domínios Significado e Verdade, geralmente foi inferior aos domínios Consciência, Graça e Transcendência. Isso indica que os domínios que apresentaram nível inferior não são importantes para os respondentes, ou não obtiveram recursos para o seu desenvolvimento. Nessa perspectiva, é possível destacar alguns aspectos:

- pessoas casadas geralmente apresentam maior nível do domínio verdade em relação aos solteiros.

- pessoas religiosas apresentam maior nível do domínio transcendência em relação aos sem religião. Logo, as pessoas que se consideram praticantes do QS no ambiente de trabalho, geralmente são pessoas que praticam alguma religiosidade. 
- pessoas com nível escolar superior geralmente apresentam maiores níveis dos domínios significado e verdade.

- pessoas que apresentaram um entendimento do QS na perspectiva existencial, apresentaram maior nível do domínio graça em relação aos que apresentaram o conceito em uma perspectiva religiosa.

- pessoas que apresentaram um entendimento do QS na perspectiva religiosa, apresentaram maior nível do domínio verdade em relação aos que apresentaram o conceito em uma perspectiva existencial.

- pessoas acima de 25 (vinte e cinco) anos apresentaram maiores níveis dos domínios transcendência e significado em relação a idades inferiores.

\section{Considerações Finais}

Este estudo mostrou que os fatores sociodemográficos (idade, religiosidade e escolaridade) influenciam na compreensão e desenvolvimento da QS, havendo destaque para o fator escolaridade, ou seja, quanto maior a escolaridade do indivíduo, maiores níveis de QS apresentaram as análises. Assim, tem-se que os discentes trabalhadores e futuros trabalhadores de Itacoatiara (AM) compreendem o QS em perspectiva intrínseca, desenvolvem em nível razoável e praticam de forma mais elevada o domínio Graça e Consciência, nos moldes de Amram e Dryer (2008).

Ainda que seja necessário indicar a necessidade de aprofundamento teórico e empírico sobre a temática envolvendo o QS e os seus desdobramentos, este estudo procurou contribuir para a compreensão de uma lógica pela qual um indivíduo que possui elevado nível de QS tende a desenvolver sua espiritualidade e, por conseguinte, uma religiosidade (ZOHAR; MARSHALL, 2017). Porém, considerou-se e constatou-se nos achados da pesquisa que o processo pode acontecer de forma inversa: primeiro, o indivíduo adere a uma religiosidade (influências socioculturais); em seguida, essa religiosidade desenvolve sua espiritualidade e, por conseguinte, apoia o desenvolvimento do QS.

Em termos de contribuições acadêmicas, este trabalho estimula busca pelo avanço de questões existenciais e espirituais do ser humano, tão importantes como quaisquer outras, pois caracterizam a integralidade humana, tal qual defendem Zohar e Marshall (2017). Levando-se em conta o perfil dos participantes da pesquisa (jovens) o trabalho provoca reflexão a respeito do impacto de eventuais práticas de espiritualidade 
em busca do bem-estar do jovem trabalhador, tal qual propuseram Cardoso e Santos (2017) e Julião, Nascimento-Santos e Paiva (2017).

Vale registrar que o presente estudo possui a limitação do cenário empírico da pesquisa, em seu contexto sociodemográfico e geográfico. Assim, recomenda-se a replicação da pesquisa para comparação dos resultados e aprofundamento das reflexões em outros contextos brasileiros e internacionais. Outra recomendação, em termos de desafios acadêmico-científicos, pode ser ilustrada pela proposição de estudos que identifiquem forma de estímulo e desenvolvimento da inteligência espiritual.

\section{Referências}

AMRAM, Y.; DRYER, D. C. The Integrated Spiritual Intelligence Scale (ISIS): Development and Preliminary Validation.In: 116th Annual Conference of the American Psychological Association, Boston, MA. 2008. Proceedings... Boston, MA. 2008.

ANTUNES, R. R.; SILVA, A. P. Inteligência Espiritual: um bem educativo. EduserRevista de educação, v. 7, n. 1, p. 30-47, 2015.

ARIAS, R.; LEMOS, V. N. Una aproximación teórica y empírica al constructo de inteligencia espiritual. Enfoques,v.27, n.1, 2015.

ARRUDA, V. C. M. A Inteligência Espiritual: espiritualidade nas organizações. São Paulo: IBRASA, 2005. 128p.

CARDOSO, E. J.; SANTOS, J. N. Práticas de Espiritualidade: Um Caminho para o Bem-Estar de Jovens Trabalhadores. REUNA, v. 22, n. 2, p. 24-43, 2017.

DAMIÃO, W. S.; VIEIRA, A. M.; SPERS, V. R. E.; CASTRO, D. S. P. Estratégias de conservação de valores organizacionais: a ação de líderes no desenvolvimento da espiritualidade em uma instituição confessional de ensino. Perspectivas Contemporâneas, v. 12, p. 67-87, 2017.

FERREIRA, D. W. A espiritualidade laica de Luc Ferry: uma proposta terrena de Salvação. Revista de Teologia e Ciências da Religião, v.6, n. 1, p. 165-179, 2016.

GIL, A. C. Métodos e técnicas de pesquisa social. São Paulo: Atlas, 1999. 216 p. HAIR, J. F.; BLACK, W. C.; BABIN, B. J.; ANDERSON, R. E.; TATHAM, R. L. Análise multivariada de dados. Porto Alegre: Bookman, 2005. 593p.

HAMMER, Ø., HARPER, D.A.T., P. D. Ryan.PAST: Paleontological Statistics Software Package for Education and Data Analysis. Palaeontologia Electronica n.4, v.1, 2001.

JULIÃO, E.; NASCIMENTO-SANTOS, J.; PAIVA, K. C. M. Relações entre Práticas de Espiritualidade e Valores Organizacionais sob a Percepção de Jovens Trabalhadores Brasileiros. Revista Ciências Administrativas, v. 23, n. 2, p. 351-366, 2017.

KALANTARKOUSHEH, S. M.; SHARGHIB, N.; SOLEIMANIB, M.; RAMEZANIB, $\mathrm{S}$. The role of spiritual intelligence on organizational commitment in employees of universities in Tehran Province, Iran. Procedia-Social and Behavioral Sciences, v. 140, p. 499-505, 2014. 
KRISHNAKUMAR, S.; NECK, C. The what, why and how of spirituality in the work place. Journal of Managerial Psychology, v. 17, n. 3, p. 153-164, 2002.

MARCONI, M. A.; LAKATOS, E. M. Técnicas de Pesquisa. São Paulo: Editora Atlas, $2002.328 \mathrm{p}$.

MOGGI, J.; BURKHARD, D. Como Integrar Liderança e Espiritualidade: a visão espiritual das pessoas e das organizações. Rio de Janeiro: Campus Elsevier, 2004. 150 p PAIVA, G. J. Religiosidade Clássica, Espiritualidade Contemporânea e Qualidade de Vida: Discussões Psicológicas. Revista RelegensThréskeia, v. 4, n. 1, p. 01-13, 2015.

PINHO, D. Inteligência Espiritual: a peça chave para a felicidade e o sucesso. Rio de Janeiro: Best Seller, 2015. 192 p.

REGO, A.; CUNHA, M. P.; SOUTO, S. Espiritualidade nas Organizações e Comprometimento Organizacional. Revista de Administração de Empresas, v.6, n.2, p. 1-27, 2007.

ROBERTS G., HESS-HERNANDEZ D. Christian Workplace Spiritual Intelligence: A Preliminary Analysis. In: DHIMAN, S.; ROBERTS, G.; CROSSMAN, J. The Palgrave Handbook of Work place Spirituality and Fulfillment. Basingstoke: Palgrave Macmillan, p. 423-447, 2018.

SAAD, M.; MASIERO, D.; BATTISTELLA, L. R. Espiritualidade baseada em evidências. Acta Fisiátrica, v. 8, n. 3, p. 107-112, 2001.

ŠILINGIENE, V.; ŠKĖRIENĖ, S. Expression of Leaders 'Spiritual Intelligence in a Context of Organizations' Services Quality: A Theoretical Approach. Procedia-Social and Behavioral Sciences, v. 156, p. 93-97, 2014.

ŠILINGIENĖ, V.; ŠKEERIENĖ, S. Expression of leaders' spiritual intelligence in a context of service organizations: A gender approach. Procedia-Social and Behavioral Sciences, v. 213, p. 758-763, 2015.

TENFEN, M. F.; VENELli-COSTA, L.; VIEIRA, A. M.; SANEMATSU, L. S. A. Espiritualidade no Ambiente de Trabalho e sua Relação com a Percepção de Sucesso na Carreira do Indivíduo. Contabilidade, Gestão e Governança, v. 22, n. 2, p. 153-170, 2019.

UPADHYAY, S.; UPADHYAY, N. A multi-criteria decision frame work to measure spiritual intelligence of university teachers. Procedia Computer Science, v. 91, p. 591598, 2016.

VASCONCELOS, A. F. The Spiritually-Based Organization: A Theoretical Review and its Potential Role in the Third Millennium. Cadernos EBAPE. BR, v. 13, n. 1, p. 183 205, 2015.

VERGARA, S. C. Métodos de pesquisa em administração. São Paulo: Atlas, 2005.

WEIGEL, J. O que é Foresight? Conheça a metodologia que modifica decisões no presente para influenciar o futuro. São Paulo: W. Futurismo, 2019.

ZOHAR, D.; MARSHALL, I. SQ: Inteligência Espiritual. Rio de Janeiro: Viva Livros, 2017. 336 p. 